\title{
Flow Cytometric Detection of Circulating Tumor Cells in Breast Cancer Patients: A Blinded Study
}

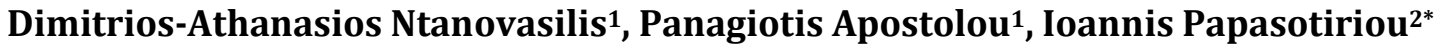 \\ ${ }^{1}$ Research Genetic Cancer Centre S.A., Florina, Greece \\ ${ }^{2}$ Research Genetic Cancer Centre International GmbH, Zug, Switzerland \\ Email: dimitrios.danovasilis@rgcc-genlab.com, * office@rgcc-genlab.com
}

How to cite this paper: Ntanovasilis, D.-A., Apostolou, P. and Papasotiriou, I. (2019) Flow Cytometric Detection of Circulating Tumor Cells in Breast Cancer Patients: A Blinded Study. Journal of Cancer Therapy, 10, 708-715.

https://doi.org/10.4236/jct.2019.108058

Received: May 21, 2019

Accepted: August 25, 2019

Published: August 28, 2019

Copyright (c) 2019 by author(s) and Scientific Research Publishing Inc. This work is licensed under the Creative Commons Attribution International License (CC BY 4.0).

http://creativecommons.org/licenses/by/4.0/

\begin{abstract}
Circulating tumor cells are cells that detach from the primary tumor site and migrate to the bone marrow or other tissues where they can initiate a metastatic site. Liquid biopsies are an emerging tool in the past decades that enables us to detect Circulating Tumor Cells in patients' blood. Flow cytometry is a powerful tool used in liquid biopsy diagnostics. This aims to prove the sensitivity and specificity of a flow cytometric panel for the detection of CTCs in breast cancer patients using healthy individuals' samples as controls. The study was blinded to the data analyzing researcher. Statistical analysis followed and results show $86.9 \%$ area under the curve which indicates that the particular method can be very promising for diagnosing breast cancer.
\end{abstract}

\section{Keywords}

CTCs, Breast Cancer, Diagnostics, Flow Cytometry

\section{Introduction}

Circulating tumor cells are a rare population of cells that shed from the primary tumor and are known to be found even at a very low number in the blood circulation of cancer patients. This subset of cancer cells is often associated with the rise of metastatic sites and cancer-related morbidity [1]. Detecting and sampling these cells is a form of liquid biopsy, which is a sensitive and minimally invasive method for early detection, disease monitoring and identification of potential drugable targets. Many studies have shown that their number can be correlated with disease progression and poor prognosis in various carcinomas [2] [3] [4] [5] [6].

Up to this date, the only FDA approved system for CTC detection and enu- 
meration is the Cell Search system. However, this platform only offers enumerations and limited phenotypic analysis based on the expression of two markers, CD45 and EpCAM [7] [8] [9].

Flow cytometry, on the other hand, is a rapid reproducible and sensitive method for detecting antigens in cells both intracellular and extracellular. It provides the opportunity for multiple antigen detection simultaneously, as well as DNA aneuploid populations [10] [11] [12] [13]. In recent years, a plethora of markers have emerged for characterizing CTCs with cytokeratins being the most commonly used [14] [15] [16] [17].

This study used a 3 color flow cytometric panel to characterize and detect CTCs in the patients' samples. CD45 was used as a marker to exclude all white blood cells [18]. CD31 was used to exclude cells of endothelial origin [19] pan-cytokeratin to detect CTCs. The investigation was performed to validate the reliability of the multicolor flow cytometric panel as an alternative fluidic based method.

\section{Materials and Methods}

\subsection{Sample Collection}

Blood samples from 61 breast cancer patients and 31 healthy individuals under sterile conditions in $50 \mathrm{ml}$ falcon tubes (Corning, NY, USA) containing $7 \mathrm{ml}$ of EDTA (Duchefa Biochemie, Kaarlem, The Netherlands) as anticoagulant. The cancer status of all the persons that took part in the study, whether they were healthy or not, was confirmed by physicians. In the case of cancer patients, the inclusion criteria involved the existence of a solid tumor. The solid tumors in the majority of cases will release CTCs in the circulation which is what the panel in this study will detect. The study was performed using samples from March to April 2019. Informed consent was acquired from all individuals participating in the study. The study was approved by the RGCC Group SA ethics committee.

\subsection{Blinding Procedure}

All the samples were given a five-digit code and were blinded before the staining procedure and the data analysis. After analyzing the data, samples were revealed for classification and statistical analysis for calculating the sensitivity, specificity and the area under the curve.

\subsection{Sample Staining}

The following mouse antihuman antibodies were used for staining: anti- pancytokeratin (Sigma, Germany) conjugated with $\mathrm{PE} / \mathrm{Cy} 5$ conjugation kit (AbCAM, Cambridge, UK), CD31-RPE (AbDSerotec, Oxford, UK) and CD45-PE/Cy7 (Invitrogen, California, USA). For intracellular staining for the cytokeratins antigens, LEUCOPERM fixation and permeabilization kit were used (AbDSerotec, Oxford, UK). Staining protocols were executed as instructed by the manufacturers' protocols. $100 \mathrm{uls}$ of whole blood were stained with $5 \mathrm{ug} / \mathrm{ml}$ of CD45-PE/Cy7 and $5 \mathrm{ug} / \mathrm{ml}$ of CD31-RPE antibodies and incubated for 20 minutes. After that, 
cells were fixed for 10 minutes using 100 ul Reagent A from the LEUCOPERM kit followed by 2 washing steps with $2 \mathrm{ml}$ of phosphate buffer saline and centrifugation at $300 \mathrm{~g}$ for 10 minutes. Cell permeabilization was performed by using $100 \mathrm{ul}$ of Reagent B from the LEUCOPERM kit. Immediately after that, the cytokeratin antibody was adding at a concentration of $5 \mathrm{ug} / \mathrm{ml}$. Incubation period was 20 minutes. 2 more washing steps followed as described above. After the last centrifugation cells were re-suspended in 500 ul of PBS solution for acquisition on the flow cytometer.

\subsection{Sample Acquisition and FC Data Analysis}

Samples were analyzed using a Beckman Coulter FC500 equiped with a blue argon laser at $488 \mathrm{~nm} .100 .000$ events were collected from each sample. FC data were then analyzed using FCS Express v6 (DeNovo software). Gating strategy was performed to exclude WBCs and endothelial cells and select the CK positive cells as shown in Figure 1. More specifically on a CD45/SSC dot plot a gate was drawn to select only the CD45- population. On a CD31/SSC dot plot a gate was drawn to select the CD31- population. Finally on a Pan-CK/SSC dot plot a gate was drawn to select the Pan-CK+ population. By using the FCS Express V6
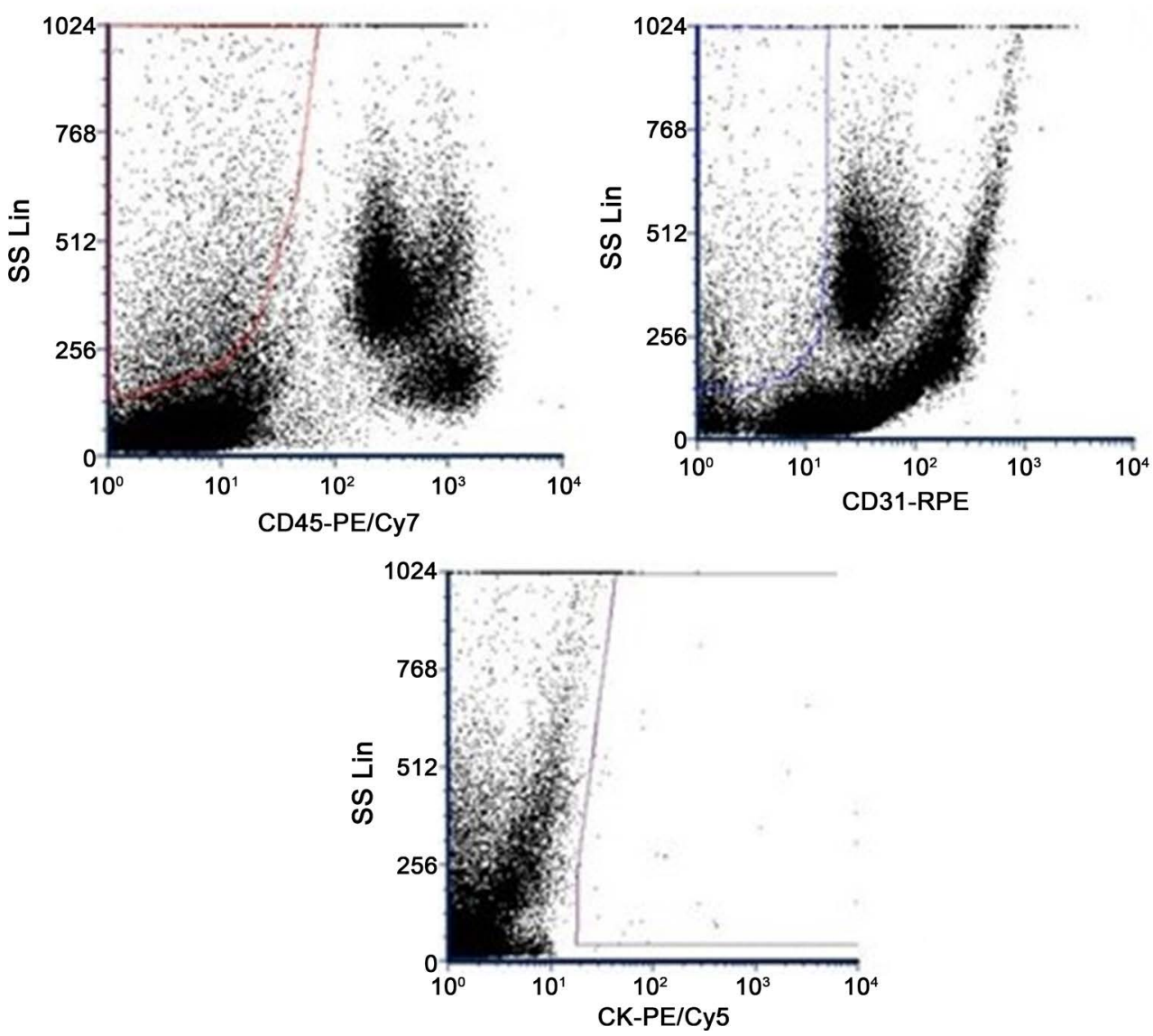

Figure 1. Gating strategy for determining the CK+ cells. Upper left dot plot shows exclusion of CD45+ cells. Upper right dot plot shows exclusion of CD31+ cells. Bottom dot plot show selection of $\mathrm{CK}+$ cells. All gates were drawn based on the negative control. 
feature of Gate View, the CD31- gate was set as a subgate of the CD45- and the Pan-CK gate as a subgate of the CD31- gate. This way the detected events had a phenotype of CD45-/CD31-/pan-CK+ (Figures 2-3).

\subsection{Statistical Analysis}

Statistical analysis was performed to calculate the sensitivity and specificity of the method as well as the area under the curve. For the statistical calculations, the SPSS software was used. P values lower than 0.05 were considered statistically significant with a confidence interval of $95 \%$

\section{Results}

After analyzing the data on FCS Express software, the identity of the candidates was revealed to the researcher and the samples were classified as cancerous and healthy. Out of the 61 cancerous samples, 55 were found positive after testing. Out of the 31 healthy samples 7 were found positive for the presence of CTCs. Results are summarized in Table 1 . Results show 0.863 areas under the curve indicating that there is $86.3 \%$ probability for a randomly selected cancerous case to be regarded with greater suspicion than a healthy one as shown in Figure 4. Sensitivity, which generally refers to the probability that a test result will be positive when CTCs are present, was high, calculated at $90.16 \%$. Specificity which refers to the probability that a test will be negative when CTCs are not present was also high, at $77.42 \%$.

\section{Discussion}

Cancer-related deaths are increasing at an exponential rate each year in the majority of countries [20]. Thus it is imperative for the clinical doctor to have tools at their disposal for diagnosing cancer at the very early stages. The gold standard up to now has been the common biopsies which can be an invasive procedure, and also dangerous for the patient if not done correctly [21]. Thus it is essential

Table 1. Summarized results of patients and healthy individuals. Tested refers to the outcome of the flow cytometry experiment while real refers to the actual condition of the person.

\begin{tabular}{ccccc}
\hline & & \multicolumn{2}{c}{ Cancer Status } & \\
\cline { 3 - 5 } Tested & Positive & Negative & 62 \\
& Positive & 55 & 7 & 30 \\
& Negative & 6 & 31 & \\
& & 61 & & \\
PPV & $88.71 \%$ & & \\
NPV & $80.00 \%$ & & \\
& Sensitivity & $90.16 \%$ & & \\
Specificity & $77.42 \%$ & & \\
\hline
\end{tabular}



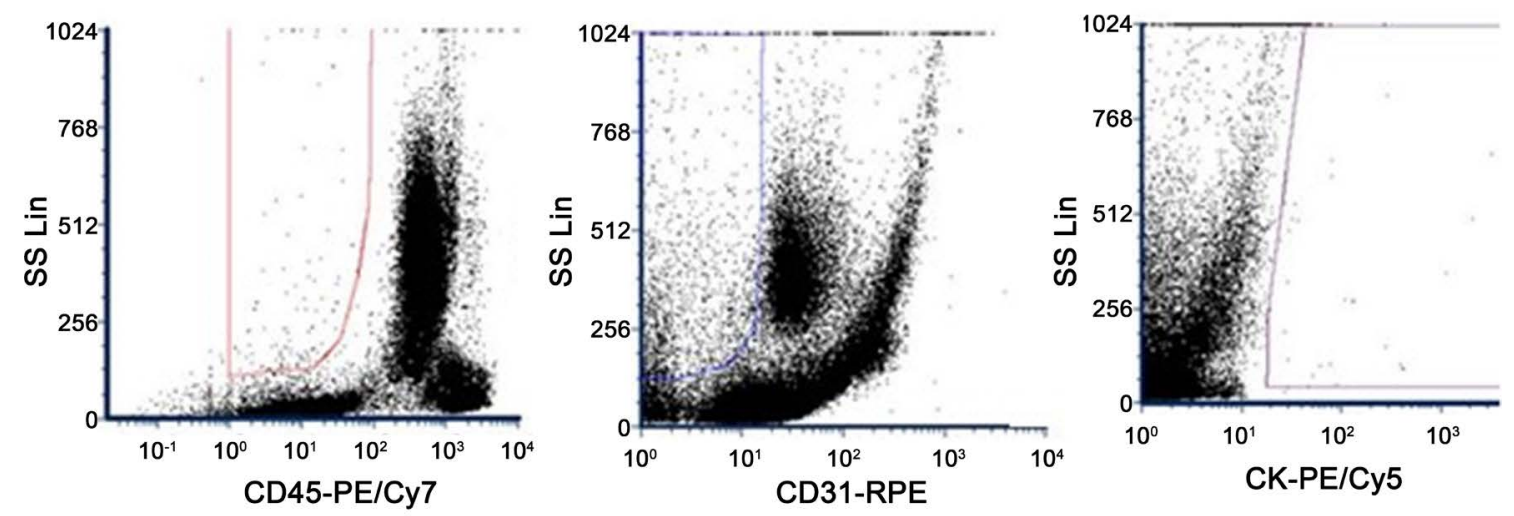

\begin{tabular}{|l|l|l|l|l|l|}
\hline Gate & $\begin{array}{l}\text { \# of } \\
\text { Events }\end{array}$ & $\begin{array}{l}\mathrm{X} \\
\text { Geometric } \\
\text { Mean }\end{array}$ & $\begin{array}{l}\text { Y } \\
\text { Geometric } \\
\text { Mean }\end{array}$ & $\begin{array}{l}\text { \% of } \\
\text { gated } \\
\text { cells }\end{array}$ & $\begin{array}{l}\text { \% of all } \\
\text { cells }\end{array}$ \\
\hline None & 100000 & n/a & n/a & 100.00 & 100.00 \\
\hline CD45(-ve) & 121 & 2.98 & 241.61 & 0.12 & 0.12 \\
\hline CD31(-ve) & 44 & 3.20 & 329.73 & 0.04 & 0.04 \\
\hline CK(+ve) & 0 & n/a & n/a & 0.00 & 0.00 \\
\hline CD227(+ve) & 1 & 1.61 & 167.00 & 0.00 & 0.00 \\
\hline
\end{tabular}

Figure 2. A healthy sample analysis. No CD45-/CD31-/CK+ cells were detected.
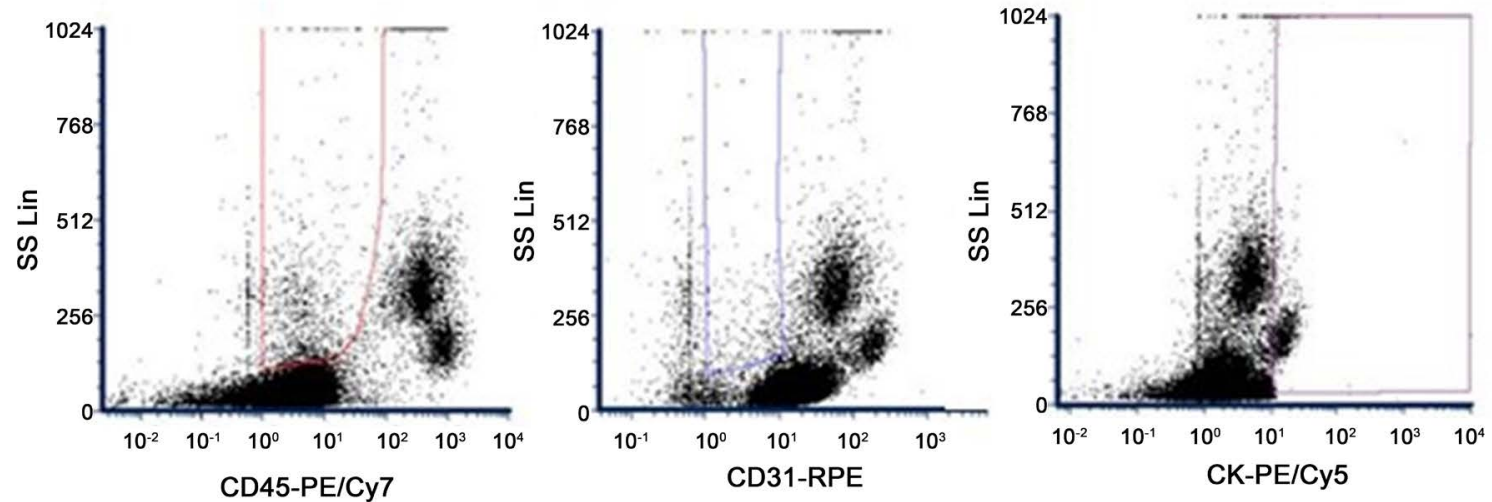

\begin{tabular}{|l|l|l|l|l|l|}
\hline Gate & $\begin{array}{l}\text { \# of } \\
\text { Events }\end{array}$ & $\begin{array}{l}\text { X } \\
\text { Geometric } \\
\text { Mean }\end{array}$ & $\begin{array}{l}\text { Y } \\
\text { Geometric } \\
\text { Mean }\end{array}$ & $\begin{array}{l}\text { \% of } \\
\text { gated } \\
\text { cells }\end{array}$ & $\begin{array}{l}\text { \% of all } \\
\text { cells }\end{array}$ \\
\hline None & 100000 & n/a & 35.47 & 100.00 & 100.00 \\
\hline CD45(-ve) & 1183 & n/a & 231.36 & 1.18 & 1.18 \\
\hline CD31(-ve) & 247 & n/a & 285.06 & 0.25 & 0.25 \\
\hline CK(+ve) & 5 & 57.54 & 1023.00 & 0.01 & 0.01 \\
\hline
\end{tabular}

Figure 3. A cancer sample analysis. Five cells were found to be CD45-/CD31-/CK+.

to evolve the new tool that has emerged in the later years, the liquid biopsies [22] [23].

Several platforms have been developed for detecting CTCs as the FDA approved Cell Search system mentioned in the introduction. This is a magnetic bead-based isolation of cells based on EpCAM expression alone followed by 


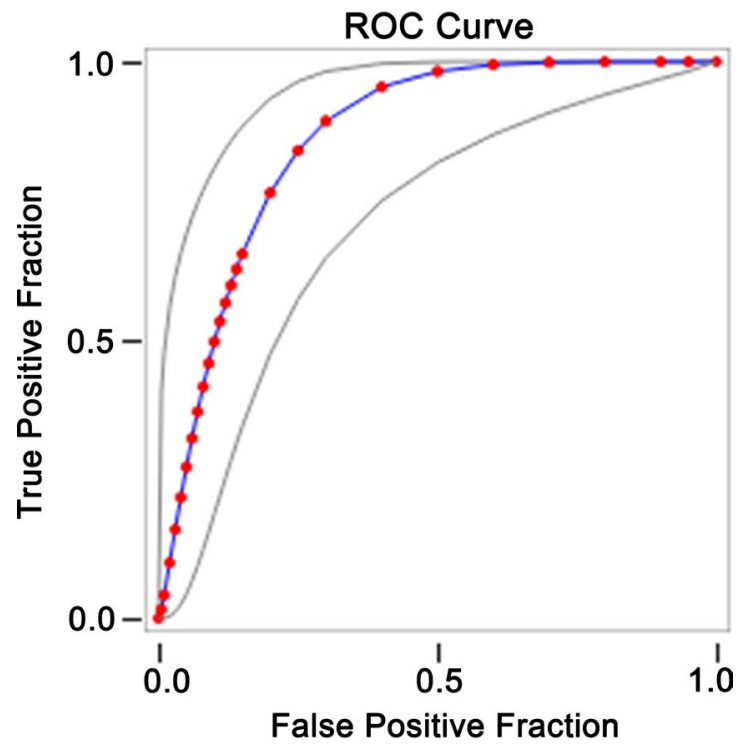

Figure 4. ROC analysis. Area under the curve was found to be $86.3 \%$. Confidence interval $95 \%$.

immunocytochemimal staining for CD45 and CK. The drawback however of this method is that a proportion of CTCs may be lost during enrichment procedure because of loss of EpCAM antigen expression [24].

This study used a highly sensitive technique, flow cytometry, coupled with a multiparameter panel to increase the sensitivity and specificity of CTC detection in breast cancer patients. Compared to previous studies as well as the gold standard for liquid biopsies it was proven to be a very sensitive method that can be used as a test to detect CTCs when they are present in a sample, leading to a non-invasive and fast procedure [25]. Of course, further studies are needed to increase the sensitivity and specificity of the method thus improving the diagnostic role of this technique.

\section{Conflicts of Interest}

The authors declare no conflicts of interest regarding the publication of this paper.

\section{References}

[1] Gupta, G.P. and Massagué, J. (2006) Cancer Metastasis: Building a Framework. Cell, 127, 679-695. https://doi.org/10.1016/j.cell.2006.11.001

[2] Krebs, M.G., et al. (2011) Evaluation and Prognostic Significance of Circulating Tumor Cells in Patients with Non-Small-Cell Lung Cancer. Journal of Clinical Oncology, 29, 1556-1563. https://doi.org/10.1200/JCO.2010.28.7045

[3] Cohen, S.J., et al. (2008) Relationship of Circulating Tumor Cells to Tumor Response, Progression-Free Survival, and Overall Survival in Patients with Metastatic Colorectal Cancer. Journal of Clinical Oncology. Official Journal of the American Society of Clinical Oncology, 26, 3213-3221.

https://doi.org/10.1200/JCO.2007.15.8923 
[4] de Bono, J.S., et al. (2008) Circulating Tumor Cells Predict Survival Benefit from Treatment in Metastatic Castration-Resistant Prostate Cancer. Clinical Cancer Research: An Official Journal of the American Association for Cancer Research, 14, 6302-6309. https://doi.org/10.1158/1078-0432.CCR-08-0872

[5] Cristofanilli, M., et al. (2004) Circulating Tumor Cells, Disease Progression, and Survival in Metastatic Breast Cancer. The New England Journal of Medicine, 351, 781-791. https://doi.org/10.1056/NEJMoa040766

[6] Poruk, K.E., et al. (2016) Circulating Tumor Cell Phenotype Predicts Recurrence and Survival in Pancreatic Adenocarcinoma. Annals of Surgery, 264, 1073-1081. https://doi.org/10.1097/SLA.0000000000001600

[7] Jansson, S., Bendahl, P.-O., Larsson, A.-M., Aaltonen, K.E. and Rydén, L. (2016) Prognostic Impact of Circulating Tumor Cell Apoptosis and Clusters in Serial Blood Samples from Patients with Metastatic Breast Cancer in a Prospective Observational Cohort. BMC Cancer, 16, 433. https://doi.org/10.1186/s12885-016-2406-y

[8] Divella, R., et al. (2014) The Presence of Clustered Circulating Tumor Cells (CTCs) and Circulating Cytokines Define an Aggressive Phenotype in Metastatic Colorectal Cancer. Cancer Causes Control, 25, 1531-1541. https://doi.org/10.1007/s10552-014-0457-4

[9] Allard, W.J., et al. (2004) Tumor Cells Circulate in the Peripheral Blood of All Major Carcinomas But Not in Healthy Subjects or Patients with Nonmalignant Diseases. Clinical Cancer Research: An Official Journal of the American Association for Cancer Research, 10, 6897-6904. https://doi.org/10.1158/1078-0432.CCR-04-0378

[10] Chen, L.M., Lazcano, O., Katzmann, J.A., Kimlinger, T.K. and Li, C.Y. (1998) The Role of Conventional Cytology, Immunocytochemistry, and Flow Cytometric DNA Ploidy in Evaluation of Body Cavity Fluids: A Prospective Study of 52 Patients. American Journal of Clinical Pathology, 109, 712-721. https://doi.org/10.1093/ajcp/109.6.712

[11] Schneller, J., Eppich, E., Greenebaum, E., Elequin, F., Sherman, A., Wersto, R. and Koss, L.G. (1987) Flow Cytometry and Feulgen Cytophotometry in Evaluation of Effusions. Cancer, 59, 1307-1313. https://doi.org/10.1002/1097-0142(19870401)59:7<1307::AID-CNCR2820590713>3. $0 . \mathrm{CO} ; 2-\mathrm{Q}$

[12] Unger, K.M., Raber, M., Bedrossian, C.W., Stein, D.A. and Barlogie, B. (1983) Analysis of Pleural Effusions Using Automated Flow Cytometry. Cancer, 52, 873-877.

https://doi.org/10.1002/1097-0142(19830901)52:5<873::AID-CNCR2820520522>3.0 .CO;2-V

[13] Krishan, A., Ganjei-Azar, P., Jorda, M., Hamelik, R.M., Reis, I.M. and Nadji, M. (2006) Detection of Tumor Cells in Body Cavity Fluids by Flow Cytometric and Immuncytochemical Analysis. Diagnostic Cytopathology, 34, 528-541.

https://doi.org/10.1002/dc.20496

[14] Fuchs, E. and Cleveland, D.W. (1998) A Structural Scaffolding of Intermediate Filaments in Health and Disease. Science, 279, 514-519. https://doi.org/10.1126/science.279.5350.514

[15] Pollard, T.D. and Cooper, J.A. (2009) Actin, a Central Player in Cell Shape and Movement. Science, 326, 1208-1212. https://doi.org/10.1126/science.1175862

[16] Herrmann, H., Strelkov, S.V., Burkhard, P. and Aebi, U. (2009) Intermediate Filaments: Primary Determinants of Cell Architecture and Plasticity. Journal of Clinical Investigation, 119, 1772-1783. https://doi.org/10.1172/JCI38214 
[17] Anderson, J.M., Heindl, L.M., Bauman, P.A., Ludi, C.W., Dalton, W.S. and Cress, A.E. (1996) Cytokeratin Expression Results in a Drug-Resistant Phenotype to Six Different Chemotherapeutic Agents. Clinical Cancer Research, 2, 97-105.

[18] Nakano, A., Harada, T., Morikawa, S. and Kato, Y. (1990) Expression of Leukocyte Common Antigen (CD45) on Various Human Leukemia/Lymphoma Cell Lines. Acta Pathologica Japonica, 40, 107-115. https://doi.org/10.1111/j.1440-1827.1990.tb01549.x

[19] Liu, L. and Shi, G.-P. (2012) CD31: Beyond a Marker for Endothelial Cells. Cardiovascular Research, 9, 3-5. https://doi.org/10.1093/cvr/cvs108

[20] Siegel, R.L., Miller, K.D. and Jemal, A. (2019) Cancer Statistics, 2019. CA: A Cancer Journal for Clinicians, 69, 7-34. https://doi.org/10.3322/caac.21551

[21] Shyamala, K., Girish, H.C. and Murgod, S. (2014) Risk of Tumor Cell Seeding through Biopsy and Aspiration Cytology. Journal of International Society of Preventive and Community Dentistry, 4, 5-11. https://doi.org/10.4103/2231-0762.129446

[22] Alimirzaie, S., Bagherzadeh, M. and Akbari, M.R. (2019) Liquid Biopsy in Breast Cancer: A Comprehensive Review. Clinical Genetics, 95, 643-660. https://doi.org/10.1111/cge.13514

[23] Marrugo-Ramírez, J., Mir, M. and Samitier, J. (2018) Blood-Based Cancer Biomarkers in Liquid Biopsy: A Promising Non-Invasive Alternative to Tissue Biopsy. International Journal of Molecular Sciences, 19, 2877. https://doi.org/10.3390/ijms19102877

[24] Cristofanilli, M. (2009) The Biological Information Obtainable from Circulating Tumor Cells. The Breast, 18, S38-S40. https://doi.org/10.1016/S0960-9776(09)70270-X

[25] Riethdorf, S., Fritsche, H., Müller, V., Rau, T., Schindlbeck, C., Rack, B., Janni, W., Coith, C., Beck, K., Jänicke, F., Jackson, S., Gornet, T., Cristofanilli, M. and Pantel, K. (2007) Detection of Circulating Tumor Cells in Peripheral Blood of Patients with Metastatic Breast Cancer: A Validation Study of the Cell Search System. Clinical Cancer Research, 13, 920-928. https://doi.org/10.1158/1078-0432.CCR-06-1695 